\title{
AT 1 receptor blockade alters metabolic, functional and structural proteins after reperfused myocardial infarction: Detection using proteomics
}

\author{
B. I. Jugdutt · G. Sawicki
}

Published online: 22 December 2006

(C) Springer Science+Business Media B.V. 2006

Erratum to: Mol Cell Biochem

DOI 10.1023/B:MCBI.0000041860.97991.7a

In this article, in Figure 3B, on page 184, the bar graph panels under the infarct zone and non-infarct zoneshould be switched. The figure should be as shown below:

The online version of the original article can be found at http:// www.dx.doi.org/10.1023/B:MCBI.0000041860.97991.7a.

B. I. Jugdutt

Division of Cardiology, Department of Medicine, University

of Alberta, Edmonton, Alberta, Canada

B. I. Jugdutt $(\bowtie) \cdot$ G. Sawicki

Department of Pharmacology, University of Alberta,

Edmonton, Alberta, Canada

e-mail: bjugdutt@ualberta.ca

G. Sawicki

The Cardiovascular Research Group, Faculty of Medicine,

University of Alberta, Edmonton, Alberta, Canada 
A. Infarct (grams)

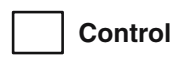

Valsartan Q Irbesartan Infarct / risk (\%) Infarct / LV (\%)
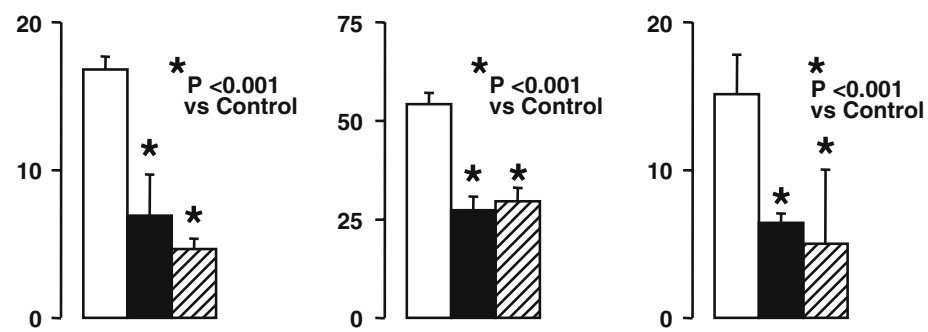

B.

Infarct zone

Border zone

Non-infarct zone
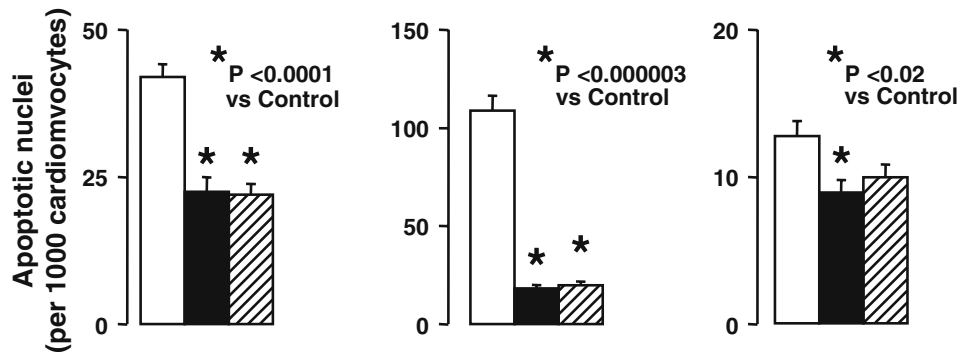